PANORAMA ECONÓMICO, Volumen V, No. 10, enero-junio, 2010, pp. 41-74

\title{
ESTIMACIÓN Y ANÁLISIS DE LA DEMANDA LABORAL DE LA \\ INDUSTRIA MANUFACTURERADE \\ TLAXCALA, 2002-2003
}

\author{
Mario M. Carrillo Huerta* \\ Alethia I. Rivero Segura**
}

\begin{abstract}
RESUMEN
En este trabajo se presentan los resultados de la estimación de la demanda laboral en la Industria Manufacturera de Tlaxcala con base en la Encuesta a Empresas Manufactureras, que forma parte del proyecto denominado Sistema de Información Laboral para Apoyar el Desarrollo Regional de Tlaxcala (SILADERT), para el periodo 2002-2003. Mediante el empleo del modelo econométrico del Sistema de Ecuaciones Aparentemente no Relacionadas (SUR), se calcularon las elasticidades de la demanda laboral, considerando la interacción de los cuatro tipos de mano de obra en la producción: Obreros Calificados Permanentes, Obreros Calificados Eventuales, Obreros No Calificados Permanentes, Obreros No Calificados Eventuales, el precio

\footnotetext{
* Profesor e investigador de la Benemérita Universidad Autónoma de Puebla, el Colegio de Tlaxcala y la Universidad de las Américas-Puebla; Miembro del Sistema Nacional de Investigadores (SNI) Nivel III. Correo electrónico: <mmch@prodigy.net.mx>.
}

** Universidad de las Américas-Puebla. Correo electrónico: <rivero_ale@hotmail.com>.
\end{abstract}


del producto y el capital. Los resultados muestran que la mano de obra calificada y no calificada son insumos complementarios y que los Obreros No Calificados Eventuales son complemento de los No Calificados de Planta.

Palabras Clave: Demanda laboral, elasticidades, economía regional, Sistema de Ecuaciones Aparentemente no Relacionadas (SUR)

Clasificación JEL: J20, J23, O18

\begin{abstract}
This paper presents the results from estimating the labor demand for the manufacturing sector of the state of Tlaxcala, for the period 2002-2003. Through the use of an econometric model of Seemingly Unrelated Regressions (SUR), the elasticities of the demand for labor were estimated, considering the interaction of four types of labor in the production process: permanent skilled workers, temporary skilled workers, permanent unskilled workers, temporary unskilled workers, the price of the product and the capital input. The results show that skilled and unskilled labor are complementary inputs and that unskilled permanent workers and unskilled temporary workers are complement.

Keywords: Labor demand, elasticity, regional economy, The Seemingly Unrelated Regressions Model (SUR).

JEL classification: J20, J23, O18.
\end{abstract}

\title{
1. INTRODUCCIÓN
}

Estudios recientes de demanda laboral afirman que los contratos temporales que otorgan los empleadores, son una herramienta para discriminar a los nuevos trabajadores de acuerdo con su potencial (Egenllandt y Riphahn, 2003). Además muestran evidencia de que los empleos temporales son un trampolín para que los trabajadores eventuales sean empleados de forma permanente, por lo que tienen un incentivo de esforzarse más que los empleados permanen- 
ESTIMACIÓN Y ANÁLISIS DE LA DEMANDA LABORAL DE LA

Industria Manufacturera de Tlaxcala, 2002-2003

tes. Gagliarducci (2005), menciona que la trayectoria para ser un empleado permanente comúnmente implica una secuencia de varios contratos temporales. Como consecuencia, la probabilidad de moverse de un empleo temporal a uno permanente aumenta con la duración de los contratos eventuales. ${ }^{1}$ Por otro lado, Ingram y Neuman (2003) concuerdan con Hamermesh (1993) en que los cambios tecnológicos favorecen el trabajo calificado en la producción; es decir, el empleo calificado es complemento del capital, lo que sugiere que los cambios tecnológicos dirigen la demanda de la capacitación (calificación) de los trabajadores. Por el contrario, el trabajo no calificado es sustituto del capital.

Desde el punto de vista de la demanda laboral se encuentra que, algunos de los empleadores pueden usar al empleo temporal en el corto plazo como una reserva laboral y como consecuencia las empresas están renuentes a mover a empleados temporales a posiciones permanentes, independientemente de las habilidades de los trabajadores. Este comportamiento se exagera cuando hay un exceso de oferta en el mercado de trabajo o cuando hay disposiciones rigurosas de seguridad en los empleos permanentes.

El objetivo de este trabajo es mostrar los efectos que tienen los componentes de la demanda laboral en la Industria Manufacturera de Tlaxcala, para 2002 y 2003. Estos efectos se deben a que los obreros calificados y no calificados son insumos sustitutos en la producción, pero contar con obreros empleados de forma permanente o eventual puede afectar la sustitución o complementación entre los tipos de mano de obra, así como la definición del tipo del insumo: insumo normal o inferior. Esto permite estudiar los efectos generados de combinar las dos dimensiones (planta-eventual, calificados-no calificados) de la mano de obra; es decir, analizar la interacción de los cuatro tipos de mano de obra en la producción: Obreros Calificados Permanentes, Obreros Calificados Eventuales, Obreros No Calificados Permanentes, Obreros No Calificados Eventuales.

\footnotetext{
${ }^{1}$ Gagliarducci (2005), encontró evidencia de que los trabajadores jóvenes necesitan más de un
} trabajo temporal para adquirir la experiencia necesaria para ser promovidos a un empleo permanente. 
El trabajo se ha organizado en cinco secciones. En la segunda sección se revisa brevemente la literatura sobre la demanda de mano de obra, y su evidencia empírica reciente al nivel general. En la tercera sección se incluye la descripción de los datos. En la cuarta sección se presenta la metodología econométrica. En la quinta sección se ofrecen los resultados obtenidos. Finalmente, en la sexta sección se presentan las conclusiones.

\section{MARCO TEÓRICO}

En los últimos años ha aumentado la literatura referente al concepto y determinantes de la demanda laboral. Para definir el concepto de demanda laboral primero se debe considerar que las empresas, quienes venden bienes y servicios, también son compradores en el mercado de trabajo. Las empresas necesitan trabajadores para hacer productos, diseñarlos, empacarlos, venderlos, hacerles publicidad y distribuirlos. De acuerdo con Hamermersh (1993), la demanda de trabajo es cualquier decisión tomada por un empleador correspondiente a los trabajadores de la compañía, el empleo de ellos, sus compensaciones y su entrenamiento. Por lo tanto, las firmas determinan la cantidad de trabajo que demandan de acuerdo con los siguientes planteamientos ¿Cuánto cuesta el trabajo?, representado en el mercado por los salarios. ¿Cuánto de éste necesitan?

En lo que resta de esta sección se presentan los dos enfoques principales de la demanda laboral (estático y dinámico), se revisa la literatura de trabajos empíricos de la demanda de trabajo y finalmente se comentan las consideraciones que deben hacerse para estimar la demanda de trabajo.

\subsection{ENFOQUE ESTÁTICO DE LA DEMANDA LABORAL}

El modelo estático de la demanda laboral implica suponer la existencia de una firma competitiva con rendimientos constantes a escala, por lo que la elasticidad-salario de la firma en equilibrio es: 
ESTIMACIÓN Y ANÁLISIS DE LA DEMANDA LABORAL DE LA

Industria Manufacturera de Tlaxcala, 2002-2003

$$
\eta_{L L}=-[1-s] \sigma-s \eta<0
$$

Donde $\sigma$ es la elasticidad de sustitución factorial; $\eta$ es la elasticidad-precio de la demanda por el bien final; y $s$ representa la proporción de la nómina sobre el valor de las ventas totales de la firma. El resultado de la ecuación (1) implica que la elasticidad-precio de la demanda por trabajo puede descomponerse en dos efectos:

1) El efecto sustitución, $-[1-s] \sigma$. Mide la variación porcentual de la razón capital-trabajo y está determinado por el cambio porcentual del costo relativo de los factores.

2) El efecto producto o efecto escala, $-s \eta$. Mide la variación porcentual de la demanda por el producto final, dado un cambio en su precio. Es inducido por un aumento en los costos de producción derivados de mayores salarios.

Dada la ecuación (1) y los efectos de la elasticidad-precio de la demanda laboral, el siguiente paso en una investigación empírica es obtener la especificación a estimar. Una primera forma de estimar la ecuación (1) es considerar la condición de productividad marginal, igual al costo marginal del problema de minimización de costos de una firma con función de producción del tipo CES:

$$
\ln L_{i}=\alpha-\sigma \ln w_{i}+\alpha \ln Y_{i}
$$

La ecuación (2) permite estimar la elasticidad de sustitución, $\sigma$, y el grado de economía de escala de la firma, $\alpha$. Ahora, dado $s$, se puede estimar la elasticidad producto-constante de la demanda de trabajo, $-[1-s] \sigma{ }^{2}$

\footnotetext{
${ }^{2}$ La ventaja de esta especificación es, que no requiere del conocimiento del precio de los otros factores de la producción, distintos del costo laboral. Sin embargo, es limitada debido a los supuestos de la función de producción (Arango y Rojas, 2003).
} 
Una especificación alterna, propuesta por Hamermesh (1993), consiste en estimar un sistema de ecuaciones de demanda laboral a partir de la siguiente ecuación:

$$
\ln L_{i}=\alpha-\sum b_{j} \ln w_{j}+\alpha \ln Y_{i}
$$

Donde $w_{i}$ es la remuneración del factor $j$. Dada la ecuación (3), se estima $\eta_{L L}=b_{i}=-[1-s] \sigma<0$ de forma directa, siempre y cuando se tenga información sobre el precio de los otros factores de la producción y del salario real.

\subsection{ENFOQUE DINÁMICO DE LA DEMANDA LABORAL}

Los ajustes de la nómina de una firma, ante cambios en los salarios, la tecnología o la demanda de sus productos, no ocurren de manera instantánea sino que toman algún tiempo. ${ }^{3}$ Adicionalmente, el empleo no responde, uno a uno, a fluctuaciones en la demanda final. Existe evidencia de un comportamiento procíclico de la productividad del trabajo, explicada por rezagos en la demanda de trabajo frente a cambios en la demanda de bienes finales (Arango y Rojas, 2003). Estos rezagos han sido modelados teóricamente e incluyen: la respuesta de los empresarios a costos de ajuste de la nómina (derivados de restricciones a la contratación) y el despido de trabajadores (conceptos como indemnizaciones por despido, costos de entrenamiento, políticas de estabilidad laboral, limitaciones sindicales a la contratación, programas subsidiados de entrenamiento en la firma, entre otros). ${ }^{4}$

${ }^{3}$ Por ejemplo, un aumento en las tarifas de energía no induce un aumento inmediato en la demanda por horas-trabajo.

4 Algunos de los costos de ajuste son explícitos y pueden ser identificados en la contabilidad, como los cursos de capacitación, adecuación de las instalaciones, publicidad de vacantes e indemnización por despido (Arango y Rojas, 2003). 
ESTIMACIÓN Y ANÁLISIS DE LA DEMANDA LABORAL DE LA

Industria Manufacturera De TlaxCALA, 2002-2003

Hamermesh (1993) planteó una forma más simple de introducir los costos de ajuste, suponiendo que provienen de la ecuación cuadrática de la nómina:

$$
C(L)=a|\dot{L}|+b L^{2}, \quad \forall a, b>0
$$

donde los costos marginales de ajuste de la demanda de trabajo son $a+2 b L$; es decir, los costos de ajustar la nómina crecen al cuadrado de su aumento debido a las deformaciones provocadas por el cambio de un periodo determinado que generan alteraciones más que proporcionales en el producto.

Suponiendo que el precio del producto se mantiene constante y que los choques provienen de variaciones en los salarios, $w_{i}$, el empresario buscará maximizar el valor descontado de sus ganancias futuras:

$$
\pi=\int_{0}^{\infty}\left\{F\left(L_{t}\right)-w L_{t}-c\left(\dot{L}_{t}\right)\right\} e^{-r t} d t
$$

donde $F(\cdot)$ es la función de producción y los beneficios futuros son descontados a la tasa $r$. Considerando la ecuación (5), y tomando en cuenta la ecuación de Euler, el nivel de empleo óptimo, $L^{*}$, satisface la condición: ${ }^{5}$

$$
F^{\prime}\left(L^{*}\right)=w+r a
$$

Por ello, la productividad marginal del trabajo en el largo plazo es igual al costo marginal de contratarlo. ${ }^{6}$ Considerando la formación de expectativas, Gould (1968) propone que la trayectoria óptima de ajuste de la nómina para el empresario, es:

\footnotetext{
${ }^{5}$ La ecuación de Euler es: $2 b L_{t}-2 b r L_{t}+F^{\prime}\left(L_{t}\right)-w-r a=0$.

${ }^{6}$ A diferencia del modelo estático, en el cual el valor de la productividad marginal es igual al salario, los costos marginales de ajuste se adicionan al salario, y al nivel de empleo óptimo, $L^{*}$.
} 


$$
L_{t}=\gamma\left[L^{*}-L_{t}\right]
$$

donde $\gamma$ es la tasa a la cual se ajusta el empleo corriente al nivel óptimo, el cual es una función implícita decreciente de $b$. La ecuación (7) es el punto de partida del enfoque dinámico de la demanda laboral. Si se sustituye $L^{*}$ en función de sus determinantes se tiene que:

$$
\Delta L_{t}=\gamma\left[G\left(X_{t}\right)-L_{t-1}\right]
$$

Suponiendo que $G(\cdot)$ es una función lineal y que los determinantes de la demanda laboral $\left(L^{*}\right)$ son valores corrientes de factores exógenos, se tiene que:

$$
L^{*}{ }_{t}=\lambda L_{t}-1+\beta X_{t}+e_{t}
$$

donde la longitud media del periodo de ajuste es de $t^{*}=\ln (0.5) \ln (\lambda)$. $^{7}$ Dada la ecuación (7) se puede derivar un modelo en donde las firmas se enfrentan a mercados imperfectos y deben efectuar pronósticos sobre los futuros valores de sus costos y sus ventas (Nickell, 1984). Así la ecuación (9) puede rescribirse como:

$$
L^{*}{ }_{t}=\lambda L_{t-1}+\sum_{m=1}^{M} \sum_{i=0}^{\infty} \mu_{i m} E t\left(X_{m, t+i}\right)+e_{i}
$$

Suponiendo que los procedimientos de pronóstico requeridos para generar la secuencia de valores esperados son los óptimos, y dado el requerimiento de

\footnotetext{
${ }^{7}$ Uno de los principales problemas para estimar la ecuación (9) es que, supone que la dinámica de las respuestas de las innovaciones en el vector $X$ son idénticas. Pero esto sucederá siempre y cuando se suponga que el empresario tiene expectativas estáticas, o que sus expectativas racionales se basan en los procesos que sólo incluyen los valores contemporáneos de $X$.
} 
ESTIMACIÓN Y ANÁLISIS DE LA DEMANDA LABORAL DE LA

Industria Manufacturera de Tlaxcala, 2002-2003

que deben basarse en información pasada de $X$, la ecuación (10) queda como sigue:

$$
L^{*}{ }_{t}=\lambda L_{t-1}+\sum_{m=1}^{M} \sum_{k=0}^{N m} \beta_{m k} X_{m, t-k}+e_{t}
$$

La ecuación (11) puede estimarse mediante un sistema de ecuaciones en diferencias con el fin de recuperar estimaciones de la elasticidad empleo-salarioproducto constante en el largo plazo, $-[1-s] \sigma$.

\subsection{EVIDENCIA EMPÍRICA DE LA DEMANDA LABORAL}

En lo que resta de esta sección se presenta la revisión de la literatura de la demanda laboral y de su estimación. ${ }^{8}$ Se presentan modelos empíricos relacionados con el tema y se propone el modelo matemático a seguir para estimar la demanda laboral de la Industria Manufacturera de Tlaxcala.

Roberts y Skuofias (1997) estimaron la demanda laboral de largo plazo para trabajadores calificados y no calificados, mediante el empleo de datos de panel para plantas pertenecientes al sector manufacturero de Colombia. El modelo establece que el sector manufacturero es la mayor fuente de empleo en general y, en particular, de empleo calificado. Mencionan que algunas de las políticas que pueden impactar el mercado laboral del sector manufacturero son las de salarios mínimos, beneficios no salariales (como sistemas de retiro o de salud), entre otros. La motivación de la investigación de Roberts y Skoufias (1997) deriva de la nula evidencia empírica sobre el ajuste del nivel de empleo de las empresas, en respuesta a cambios en el costo del trabajo o en la demanda de lo que producen. Como resultado, hay evidencia virtual no directa de cómo las firmas individuales o plantas ajustan el empleo, como res-

\footnotetext{
${ }^{8}$ Todo lo anterior es bajo el supuesto de competencia perfecta. (Ver Varian, 1992).
} 
puesta a cambios en el costo del trabajo o de la demanda de su producto. ${ }^{9}$ (Sus resultados se muestran en la Tabla 1 ).

El método econométrico utilizado por Roberts y Skuofias (1997) emplea las técnicas econométricas de MCO y Variables Instrumentales. Los autores calculan la magnitud y la significancia estadística de los parámetros estimados, e indican que hay un ajuste importante del empleo al nivel de planta como respuesta a las diferencias en cantidades de producto, salarios u otras características de la planta. ${ }^{10}$ Encuentran que la elasticidad-salario es más grande para trabajadores no calificados, y que la respuesta del empleo (al nivel micro) a cambios en el producto o en los precios de factores es considerable.

Dunne (1993), estimó una función de demanda laboral de largo plazo para actividades de producción considerando trabajadores calificados y no calificados. Esta investigación estima, para Estados Unidos, las elasticidades del salario y del producto de la demanda de trabajo de 41000 plantas manufactureras correspondientes a 1975 y de más de 30000 plantas en 1981. Supone que la planta enfrenta precios exógenos de cada uno de los insumos y que al inicio de cada año elige la cantidad de insumos necesarios para minimizar el costo de producir cierto nivel de producción.

La demanda fue estimada por separado para tres diferentes categorías: a) trabajadores de producción; b) horas de trabajo totales por trabajador; c) trabajadores que no son de producción. Dunne (1993) concluye que los factores no observables al nivel de firma son muy importantes y, cuando son ignorados, introducen un sesgo sistemático en los coeficientes de la demanda de trabajo.

Pencavel y Craig (1994), realizaron un estudio de la demanda laboral en la industria manufacturera de madera laminada en el Pacífico Norte de los Esta-

\footnotetext{
9 Además las elasticidades de la demanda, estimadas a partir de datos al nivel de planta, miden con más exactitud la respuesta de los productores individuales a cambios exógenos en el salario que las elasticidades estimadas a partir de datos al nivel de industria. Los datos utilizados son al nivel micro tipo panel para 1981-1987.

${ }^{10}$ Las estimaciones de largo plazo de la demanda de trabajo al nivel micro indican una mayor respuesta del producto que cuando se reporta usando datos agregados o sectoriales.
} 
ESTIMACIÓN Y ANÁLISIS DE LA DEMANDA LABORAL DE LA

Industria Manufacturera de Tlaxcala, 2002-2003

dos Unidos. Con el empleo de una base de datos que contiene información sobre 173 empresas (incluidas 43 cooperativas) correspondientes al periodo 1972-1980, Pencavel y Craig (1994) analizaron los promedios de empleo, horas anuales por trabajador, insumos, producto real, producto por trabajador, producto por insumo, horas per capita por insumo, ganancias reales por hora, precios reales del producto, y ganancias anuales reales por trabajador.

Pencavel y Craig (1994) calculan las elasticidades del precio, del producto y de los insumos con respecto a los salarios reales por hora, empleo, horas por trabajador, ganancias anuales reales por trabajador y nivel de producto, comparando las empresas cooperativas con las convencionales.

Concluyen que, en respuesta a los cambios en los precios del producto y de los insumos, las cooperativas ajustan los salarios pero las empresas convencionales ajustan las horas trabajadas por los empleados de producción y, ante este cambio, ambos tipos de empresas ajustan sus insumos y su nivel de producto.

Arango y Rojas (2003), estimaron un modelo dinámico de la demanda laboral de la Industria Manufacturera de Colombia para el periodo 1977-1999. El objetivo fue estudiar el comportamiento de la demanda laboral durante el periodo antes citado, para determinar hasta qué punto el comportamiento del empleo industrial fue resultado de cambios de los precios relativos de los factores o de cambios estructurales en los parámetros de la demanda de trabajo derivados de cambios en la función de producción.

Sus resultados muestran cambios significativos en la estructura productiva de la industria manufacturera durante el periodo estudiado. Dichos cambios presentan un alto grado de heterogeneidad entre categorías de establecimientos y algunos de los efectos, al parecer, no son permanentes o se revierten en el tiempo. También encontraron evidencia de que hay una relación estrecha entre los parámetros y el grado de liberalización comercial. A mayor liberalización comercial, mayor elasticidad de sustitución factorial. Por otra parte, la mayor liberalización reduce las economías de escala de la firma y existe evidencia de que aumenta la velocidad de ajuste de la firma industrial frente a 
choques exógenos al mercado laboral. ${ }^{11}$ Además, Arango y Rojas (2003) encontraron evidencia significativa de un proceso técnico ahorrador de trabajo en la firma manufacturera que empieza en los ochenta pero se profundiza durante los noventa. ${ }^{12}$

Finalmente, Berndt (1991) estima demandas de trabajo a partir de dos tipos de funciones de costos: Leontief Generalizada y Translogarítmica. ${ }^{13}$ Propone un modelo con cuatro insumos: capital $(K)$, trabajo $(L)$, energía $(E)$ e insumos intermedios $(M)$. En ambos casos Berndt (1991) aplica el lema de Shephard y obtiene un Sistema de Ecuaciones Aparentemente No Relacionadas, a partir de las cuales obtiene las elasticidades. Los resultados obtenidos presentan evidencia de que el capital y la energía son insumos complementarios, mientras que el capital y el trabajo son sustitutos (igual que la energía y el trabajo). Ambos modelos se estiman a partir de la técnica econométrica de sistemas aparentemente no relacionados (Seemingly Unrelated Regresión, SUR).

En la Tabla 1, se resumen los principales resultados de la revisión de la literatura más relevante de demanda laboral.

${ }^{11}$ Igualmente observaron que, en el decenio de los noventa, los establecimientos con poco tiempo en el mercado lograron mayores velocidades de ajuste de su demanda laboral frente a choques de largo plazo que los que ya tenían varios años en el mismo mercado.

${ }^{12}$ Esto se debe a que la mayor flexibilidad del establecimiento industrial para ajustar su nómina hace que los trabajadores enfrenten un mayor grado de incertidumbre en sus condiciones laborales, frente a choques de precios relativos o fluctuaciones de la actividad económica.

${ }^{13}$ La función de producción translogarítmica fue publicada por Christensen, Jorgenson y Lau en 1973, donde la expresión matemática para $n$ insumos es la siguiente:

$$
\ln Y=A+\sum_{i=1}^{n} \alpha_{i} \ln x_{i}+\frac{1}{2}\left[\sum_{i=1}^{n} \sum_{j=1}^{n} \beta_{i j} \ln x_{i} \ln x_{j}\right] \text { donde } \sum_{i=1}^{n} \alpha_{i}=1 \text { y } \sum_{i}^{n} \beta_{i j}=\sum_{i}^{n} \beta j i=0 .
$$

Los coeficientes $\boldsymbol{\alpha}_{\boldsymbol{i}}$ representan la elasticidad del producto con respecto al i-ésimo insumo. El término $\boldsymbol{\beta}_{i j}$ indica la complementariedad del insumo $i$ y el insumo $j$ con respecto al producto. $\mathrm{Si}$ tienen signo positivo, quiere decir que ambos factores son sustitutos; si el signo es negativo, entonces son insumos complementarios. 
ESTIMACIÓN Y ANÁLISIS DE LA DEMANDA LABORAL DE LA

Industria Manufacturera de Tlaxcala, 2002-2003

\section{TABLA 1}

\section{Principales resultados de los estudios de demanda laboral}

\begin{tabular}{|c|c|c|c|c|c|}
\hline \multirow[t]{2}{*}{ Estudio } & \multirow[t]{2}{*}{ Descripción } & \multirow[t]{2}{*}{ Resultados } & \multicolumn{3}{|c|}{$\begin{array}{l}\text { Parámetros estimados } \\
\text { mediante Técnica } \\
\text { Econométrica }\end{array}$} \\
\hline & & & OLS & IV & SUR \\
\hline \multirow{4}{*}{$\begin{array}{l}\text { Roberts y } \\
\text { Skoufias } \\
\text { (1997) }\end{array}$} & \multirow{4}{*}{$\begin{array}{l}\text { Estimaron la demanda de } \\
\text { largo plazo para los } \\
\text { trabajadores calificados y } \\
\text { no calificados de las } \\
\text { plantas pertenecientes al } \\
\text { sector manufacturero de } \\
\text { Colombia. 1981-1987 } \\
\end{array}$} & \begin{tabular}{|lccc}
$\begin{array}{l}\text { Elasticidad directa } \\
\text { trabajadores calificados }\end{array}$ & de & los \\
\end{tabular} & -0.279 & -0.423 & - \\
\hline & & \begin{tabular}{|lll} 
Elasticidad directa de los \\
trabajadores no calificados
\end{tabular} & -0.564 & -0.65 & - \\
\hline & & Elasticidad cruzada de calificados & -0.134 & -0.273 & - \\
\hline & & $\begin{array}{|llll|}\begin{array}{l}\text { Elasticidad } \\
\text { calificados }\end{array} & \text { cruzada } & \text { de } & \text { no } \\
\end{array}$ & -0.047 & -0.034 & - \\
\hline \multirow{4}{*}{$\begin{array}{l}\text { Dunne } \\
\text { (1993) }\end{array}$} & \multirow{4}{*}{$\begin{array}{l}\text { Estima la función de } \\
\text { demanda de largo plazo de } \\
\text { los trabajos de producción, } \\
\text { a partir de datos micro y } \\
\text { encuestas a } \\
\text { establecimientos de EUA. } \\
\text { 1981-1985 }\end{array}$} & $\begin{array}{l}\text { Elasticidad directa de los } \\
\text { trabajadores calificados. } 1975\end{array}$ & -0.621 & - & - \\
\hline & & $\begin{array}{|lccc|}\begin{array}{l}\text { Elasticidad directa } \\
\text { trabajadores calificados. }\end{array} & \text { de } & \text { los } \\
\end{array}$ & -0.609 & - & - \\
\hline & & $\begin{array}{l}\text { Elasticidad directa de los } \\
\text { trabajadores no calificados } 1975\end{array}$ & -0.481 & - & - \\
\hline & & $\begin{array}{l}\text { Elasticidad directa de los } \\
\text { trabajadores no calificados } 1981\end{array}$ & -0.546 & - & - \\
\hline $\begin{array}{l}\text { Arango y } \\
\text { Rojas } \\
(2003)\end{array}$ & $\begin{array}{l}\text { Estimaron la demanda } \\
\text { laboral de largo plazo de la } \\
\text { Industria Manufacturera de } \\
\text { Colombia para el periodo } \\
\text { 1977-1999 }\end{array}$ & $\begin{array}{l}\text { Elasticidad directa de los } \\
\text { trabajadores de producción }\end{array}$ & -0.33 & - & - \\
\hline \multirow{2}{*}{$\begin{array}{l}\text { Bernt } \\
(1991)\end{array}$} & \multirow{2}{*}{$\begin{array}{l}\text { Estimó la demanda de } \\
\text { trabajo utilizando dos } \\
\text { funciones de costos: } \\
\text { Leontief Generalizada y } \\
\text { Translogarítmica } \\
\end{array}$} & $\begin{array}{l}\text { Elasticidad directa } \\
\text { Leontief Generalizada } \\
\end{array}$ & - & - & -0.38 \\
\hline & & $\begin{array}{l}\text { Elasticidad } \\
\text { Translogarítmica }\end{array}$ & - & - & -0.45 \\
\hline
\end{tabular}

Como se pudo observar, luego de la revisión de la literatura, la dificultad de estimar una demanda laboral se encuentra en la selección de los niveles de análisis, las bases de datos, la unidad de medida de las variables, el espacio y la temporalidad del estudio. Otro factor importante a considerar es el análisis de largo plazo de la demanda laboral. Este análisis muestra la velocidad e intensidad de la respuesta de la demanda ante choques exógenos en el tiempo, pero el 
análisis se puede trasladar a corte transversal, aunque en este caso se tendrá especial cuidado con las elasticidades y habrá que confrontar los resultados con la teoría económica de la demanda laboral.

Como resultado de las investigaciones arriba citadas, se generan las siguientes hipótesis:

- H1: La mano de obra de la Industria Manufacturera de Tlaxcala es un nsumo normal, sin importar el grado de calificación y sin importar el tipo de contrato.

- H2: La mano de obra calificada y no calificada de la Industria Manufacturera de Tlaxcala, son sustitutos entre sí sin importar su tipo de contrato.

- H3: Los trabajadores con contratos eventuales en la Industria Manufacturera de Tlaxcala, son insumos sustitutos de los obreros con contratos permanentes sin importar su nivel de calificación.

- H4: La mano de obra calificada es complemento del capital y la mano de obra no calificada es sustituto del capital.

\subsection{CONSIDERACIONES PARA ESTIMAR LA DEMANDA LABORAL}

Los problemas que el investigador enfrenta al estimar la demanda de trabajo incluyen: a) la elección de los datos y su agregación y b) el error de medida y la estimación de la función. Hamermesh (1993) considera, respecto a los datos, distinguir si son de una serie de tiempo o de un corte transversal; el segundo punto es saber si los datos corresponden a industrias o a hogares. Es importante tener en mente que el propósito es estimar los parámetros que caracterizan a la demanda laboral a nivel de firma. En este sentido, los investigadores han utilizado:

1. Observaciones actuales de firmas o establecimientos

2. Datos agregados de establecimientos al nivel de industria

3. Los mismos datos agregados pero para toda la economía 
ESTIMACIÓN Y ANÁLISIS DE LA DEMANDA LABORAL DE LA

Industria Manufacturera De TlaxcAla, 2002-2003

Dado lo anterior, se enfrenta el problema de cómo medir el trabajo, así como su precio. El caso más sencillo es medir las cantidades de trabajo $(L)$ como el número de trabajadores totales u horas trabajadas. Lo anterior bajo el supuesto que los trabajadores son homogéneos, es decir, trabajan las mismas horas en el mismo periodo; pero si son heterogéneos y el nivel de empleo está correlacionado con los precios de los factores o con la producción, entonces habrá sesgo en los parámetros. Se pueden usar los salarios reportados o las tasas promedio de los salarios. Para esto, Hamermesh (1993) propone un esquema para realizar estudios sobre demanda laboral (ver Figura 1).

\section{FigURA 1}

\section{Esquema de Análisis de Datos de Estudios sobre Demanda Laboral}

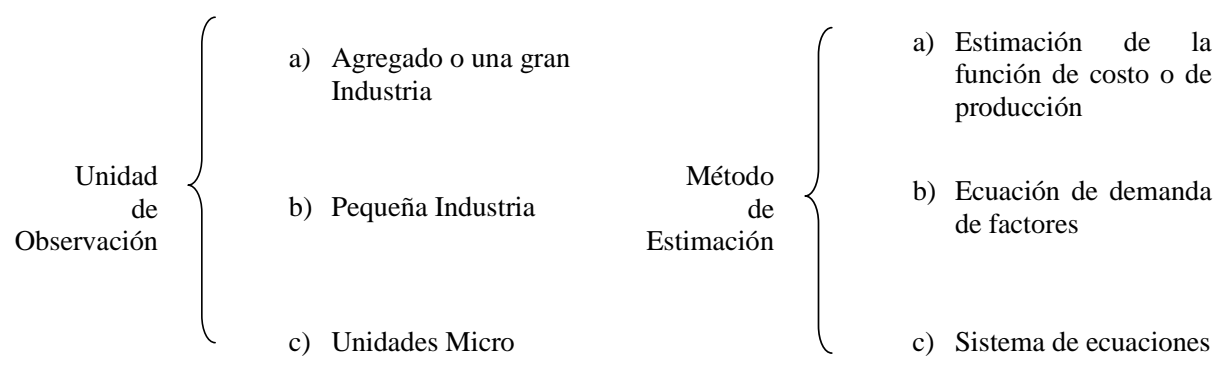

Fuente
de
Datos $\left\{\begin{array}{l}\text { a) Establecimiento } \\ \text { b) Hogares }\end{array}\right.$ Localización $\left\{\begin{array}{l}\text { a) A nivel país } \\ \text { b) Cualquier lugar }\end{array}\right.$


Además de considerar las clasificaciones anteriores para estimar la demanda laboral, se debe especificar el tipo de la función de producción a estimar (ver Figura 2). Debido a que los datos de la encuesta empleada para el presente trabajo de investigación muestran que el nivel de producto $(\mathrm{Y})$ es endógeno y los niveles de los insumos son exógenos, se estima la demanda laboral de la 3ustria Manufacturera de Tlaxcala a partir de una función de producción.

\section{Figura 2}

\section{Tipos de Funciones de Producción y Costos}

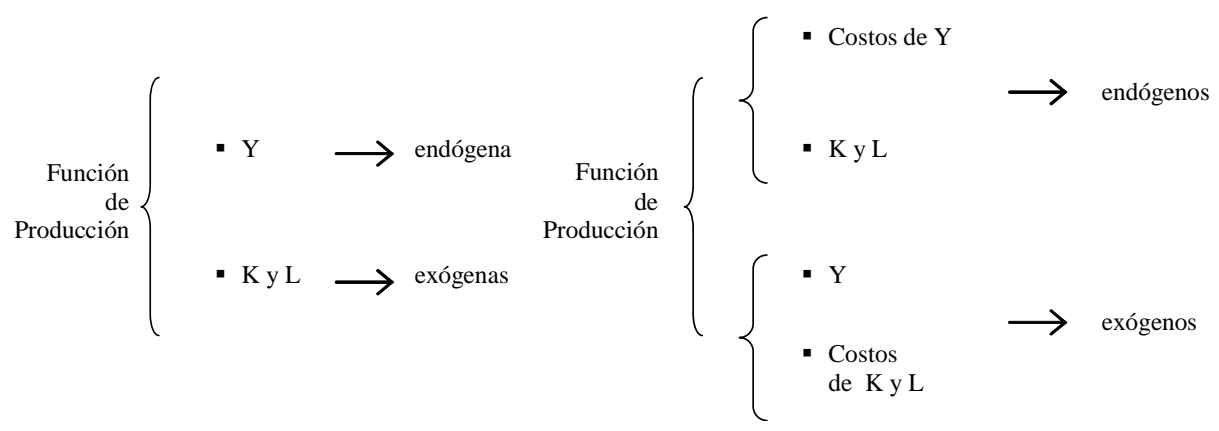

\section{DESCRIPCIÓN DE LOS DATOS}

La información que se empleó para la investigación se obtuvo de la Encuesta a Empresas Manufactureras, que forma parte del proyecto denominado Sistema de Información Laboral para Apoyar el Desarrollo Regional de Tlaxcala (SILADERT). En la encuesta del estudio del caso de Tlaxcala se incluyeron 690 empresas manufactureras ubicadas en las diferentes regiones de esa entidad. El Esquema General del SILADERT está conformado por cuatro elementos fundamentales: 
ESTIMACIÓN Y ANÁLISIS DE LA DEMANDA LABORAL DE LA

Industria Manufacturera de Tlaxcala, 2002-2003

1. La demanda actual de mano de obra (DA)

2. La oferta actual de formación y capacitación laboral (OA)

3. La demanda futura de mano de obra (DF)

4. La oferta futura de formación y capacitación laboral (OF)

Estos cuatro elementos proveen información al nivel de rama de la actividad económica de los tres sectores (primario, secundario y terciario) y de cada una de las regiones que conforman la entidad. También sobre los niveles de calificación de los trabajadores. La Encuesta fue levantada en el 2003, y capta datos del 2002 y del 2003. Para la presentación del marco de referencia, primero se presentarán datos al nivel agregado del Sector Manufacturero de Tlaxcala y, posteriormente la información se presentará por rama. Entre 1993 y 2003, la Industria Manufacturera representó la actividad económica más relevante en el estado de Tlaxcala (ver Tabla 2).

De acuerdo con el Censo Económico levantado por INEGI en 2004, en el año 2003 había en Tlaxcala un total de 38315 Unidades Económicas (UE) no agropecuarias que dieron empleo a 125008 personas, recibiendo remuneraciones por 3676 millones de pesos (ver Tabla 3). Las 5525 UE de la Industria Manufacturera representaron 14\% del total de Unidades, ocuparon al 40.3\% del personal total y participaron con el $68.4 \%$ del total de remuneraciones. Las condiciones laborales de las personas empleadas por las UE manufactureras resultaron superiores al promedio estatal: trabajaron en UE de mayor tamaño (9.1 contra 3.3), el peso relativo de los trabajadores no remunerados fue inferior (17.94\% contra $44.1 \%$ ) y los niveles de remuneraciones fueron más elevados (percepciones equivalentes a 3.44 salarios mínimos contra 2.03).

$\mathrm{Al}$ interior de la Industria Manufacturera prácticamente dos tercios de las UE (66.5\%) desarrollaban actividades tradicionales en 2003, concentrándose en dos subsectores: industria alimentaria (50\%) y fabricación de prendas de vestir (10.6\%). Estos subsectores también fueron los que dieron más empleo en la industria manufacturera, absorbiendo el $15.7 \%$ y el $28.5 \%$ del total de los trabajadores, respectivamente. La industria alimentaria destaca adicionalmente por el alto nivel de precariedad de los empleos que generó, ya que el 64\% del 
TABLA 2

\section{Distribución relativa del PIB de Tlaxcala en valores constantes de 1993, por sectores económicos (gran división), para el periodo 1993-2003}

\begin{tabular}{l|c|c|c|c|c|c|c|c|c|c|c}
\hline Sectores Económicos (G. D.) & $\mathbf{1 9 9 3}$ & $\mathbf{1 9 9 4}$ & $\mathbf{1 9 9 5}$ & $\mathbf{1 9 9 6}$ & $\mathbf{1 9 9 7}$ & $\mathbf{1 9 9 8}$ & $\mathbf{1 9 9 9}$ & $\mathbf{2 0 0 0}$ & $\mathbf{2 0 0 1}$ & $\mathbf{2 0 0 2}$ & $\mathbf{2 0 0 3}$ \\
\hline Total (Porcentaje) & $\mathbf{1 0 0 . 0}$ & $\mathbf{1 0 0 . 0}$ & $\mathbf{1 0 0 . 0}$ & $\mathbf{1 0 0 . 0}$ & $\mathbf{1 0 0 . 0}$ & $\mathbf{1 0 0 . 0}$ & $\mathbf{1 0 0 . 0}$ & $\mathbf{1 0 0 . 0}$ & $\mathbf{1 0 0 . 0}$ & $\mathbf{1 0 0 . 0}$ & $\mathbf{1 0 0 . 0}$ \\
\hline $\begin{array}{l}\text { GD1 Agropecuaria, } \\
\text { silvicultura y pesca }\end{array}$ & 8.5 & 8.1 & 8.3 & 7.8 & 6.7 & 6.2 & 5.4 & 6.6 & 7.2 & 5.7 & 7.4 \\
GD2 Minería & 0.2 & 0.2 & 0.2 & 0.2 & 0.1 & 0.1 & 0.1 & 0.2 & 0.2 & 0.2 & 0.2 \\
$\begin{array}{l}\text { GD3 Industria } \\
\text { Manufacturera }\end{array}$ & 26.5 & 26.4 & 26.3 & 28.2 & 28.8 & 30.0 & 30.6 & 29.7 & 29.2 & 29.0 & 26.9 \\
$\begin{array}{l}\text { GD4 Construcción } \\
\text { GD5 Electricidad, gas y agua }\end{array}$ & 1.1 & 1.2 & 1.4 & 1.3 & 1.3 & 1.3 & 1.4 & 1.4 & 1.5 & 1.5 & 1.9 \\
$\begin{array}{l}\text { GD6 Comercio, restaurantes } \\
\text { y hoteles }\end{array}$ & 14.4 & 14.7 & 12.8 & 12.7 & 13.1 & 13.0 & 12.8 & 13.6 & 13.7 & 13.4 & 14.0 \\
$\begin{array}{l}\text { GD7 Transporte, almacenaje } \\
\text { y comunicaciones }\end{array}$ & 8.0 & 8.0 & 8.2 & 8.6 & 8.9 & 9.3 & 9.3 & 9.5 & 9.9 & 10.2 & 10.5 \\
$\begin{array}{l}\text { GD8 Servicios financieros, } \\
\text { seguros, actividades } \\
\text { inmobiliarias y de alquiler }\end{array}$ & 16.3 & 16.4 & 17.7 & 16.5 & 15.6 & 15.7 & 15.3 & 15.0 & 15.1 & 16.2 & 16.2 \\
$\begin{array}{l}\text { GD9 Servicios comunales, } \\
\text { sociales y personales } \\
\text { Servicios bancarios } \\
\text { imputados }\end{array}$ & 20.2 & 20.5 & 21.3 & 20.7 & 21.7 & 21.2 & 20.9 & 20.5 & 19.3 & 20.3 & 19.5 \\
\hline
\end{tabular}

Fuente: INEGI. Censo Económico 2004, Estado de Tlaxcala.

personal ocupado eran trabajadores no remunerados y percibieron, en promedio, ingresos equivalentes a 1.82 salarios mínimos. En promedio, los subsectores orientados a la producción de bienes intermedios, aunque sólo contribuyeron con $21.5 \%$ del personal ocupado en el sector manufacturero, fueron los que presentaron los mejores niveles de remuneración de la fuerza de trabajo ya que sus trabajadores recibieron el equivalente a 5.08 salarios mínimos. 
EsTIMACIÓN Y ANÁLISIS DE LA DEMANDA LABORAL DE LA

Industria Manufacturera de Tlaxcala, 2002-2003

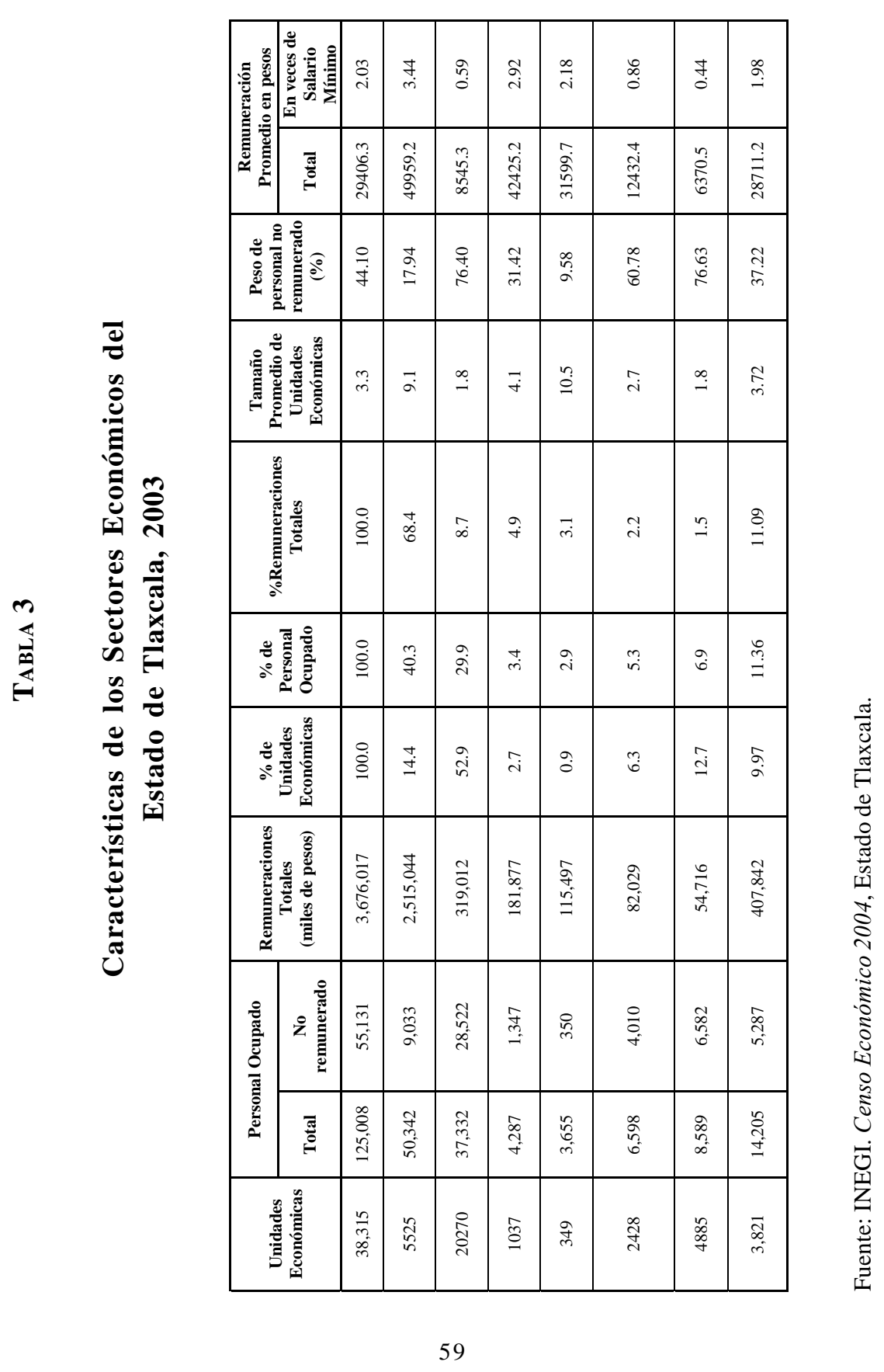


La información generada por la Encuesta SILADERT 2003 muestra que, la mayoría de los trabajadores de producción ocupados por el sector manufacturero de Tlaxcala (74.5\%) eran trabajadores de planta, mientras que el restante $25.5 \%$ eran trabajadores eventuales (ver Tabla 4). De igual manera, la mayoría de los trabajadores (75.2\%) fueron considerados como calificados para desempeñar sus funciones y el $24.8 \%$ restante como no calificados. Al desagregar la información de acuerdo al tipo de plaza, se detecta que el problema de la falta de calificación se presentó en mayor medida en los trabajadores eventuales con un 44\%, frente al $18.2 \%$ de los trabajadores de planta.

La Encuesta SILADERT 2003 indica también que, un mayor grado de estabilidad en el empleo y un nivel más alto de calificación se asocia con mejores niveles de remuneraciones en el sector manufacturero (ver Tabla 5). Por un lado, se tiene que los trabajadores de planta percibieron, en promedio, el equivalente a 3.3 salarios mínimos, mientras que los trabajadores eventuales recibieron 2.4 salarios mínimos.

Finalmente, los trabajadores calificados percibieron ingresos equivalentes a 3.4 salarios mínimos, cifra superior a los 2.4 salarios mínimos que recibieron los trabajadores no calificados. ${ }^{14}$

\section{ESTRATEGIA ECONOMÉTRICA}

La estrategia analítica seguida en la investigación interrelaciona el análisis teórico con la evidencia empírica de la demanda laboral, presentado en la sección anterior, desarrollando los siguientes puntos: a) verificar las hipótesis descritas en la sección de marco teórico, b) deducir la forma funcional adecuada para la

\footnotetext{
${ }^{14}$ Al considerar conjuntamente el tipo de plaza con el nivel de calificación se amplía la brecha entre las remuneraciones, ya que los trabajadores de planta calificados obtuvieron, en promedio, la remuneración más elevada (4 salarios mínimos), mientras que los trabajadores eventuales sin calificación percibieron, en promedio, la remuneración más baja (2.2 salarios mínimos).
} 
ESTIMACIÓN Y ANÁLISIS DE LA DEMANDA LABORAL DE LA Industria Manufacturera De TlaxcAla, 2002-2003

\section{TABLA 4}

Trabajadores de producción por tipo de plaza y nivel de calificación, 2003

\begin{tabular}{|l|c|c|c|}
\hline \multirow{2}{*}{\multicolumn{1}{|c|}{ Tipo de plaza }} & \multicolumn{3}{c|}{ Nivel de calificación } \\
\cline { 2 - 4 } & Total & Calificado & \multirow{2}{*}{ No calificado } \\
\hline Total & 17,390 & 13,084 & 4,306 \\
\hline Planta & 12,947 & 10,594 & 2,353 \\
\hline Eventual & 4,443 & 2,490 & 1,953 \\
\hline
\end{tabular}

Términos relativos (\%)

\begin{tabular}{|l|c|c|c|}
\hline \multirow{2}{*}{\multicolumn{1}{|c|}{ Tipo de plaza }} & \multicolumn{3}{c|}{ Nivel de calificación } \\
\cline { 2 - 4 } & Total & Calificado & No calificado \\
\hline Total & 100.0 & 75.2 & 24.8 \\
\hline Planta & 100.0 & 81.8 & 18.2 \\
\hline Eventual & 100.0 & 56.0 & 44.0 \\
\hline
\end{tabular}

Términos relativos $(\%)$

\begin{tabular}{|l|c|c|c|}
\hline \multirow{2}{*}{\multicolumn{1}{|c|}{ Tipo de plaza }} & \multicolumn{3}{c|}{ Nivel de calificación } \\
\cline { 2 - 4 } & Total & Calificado & No calificado \\
\hline Total & 100.0 & 100.0 & 100.0 \\
\hline Planta & 74.5 & 81.0 & 54.6 \\
\hline Eventual & 25.5 & 19.0 & 45.4 \\
\hline
\end{tabular}

Fuente: Cálculos propios. Encuesta de arranque a empresas manufactureras (SILADERT). 
Mario M. Carrillo Huerta/Alethia I. Rivero Segura

TABLA 5

\section{Salario promedio de los trabajadores de producción por tipo de plaza y nivel de calificación}

\begin{tabular}{|l|r|c|c|c|c|c|}
\hline \multirow{2}{*}{ Tipo de plaza } & \multicolumn{3}{|c|}{ Nivel de calificación } & \multicolumn{3}{c|}{ En términos relativos } \\
\cline { 2 - 7 } & Total & Calificado & $\begin{array}{c}\text { No } \\
\text { calificado }\end{array}$ & Total & Calificado & No calificado \\
\hline Total & 116.02 & 136.42 & 95.62 & 2.9 & 3.4 & 2.4 \\
\hline Planta & 133.56 & 162.55 & 104.56 & 3.3 & 4.0 & 2.6 \\
\hline Eventual & 98.48 & 110.29 & 86.67 & 2.4 & 2.7 & 2.2 \\
\hline
\end{tabular}

Fuente: Encuesta de arranque a empresas manufactureras (SILADERT).

estimación de las demandas laborales y c) plantear la mejor estrategia econométrica para estimar los parámetros de las elasticidades de la demanda laboral en la industria manufacturera de Tlaxcala.

Por lo tanto, primero se presentará la forma funcional del modelo econométrico de demanda laboral de la Industria Manufacturera en Tlaxcala. ${ }^{15}$ La estimación parte de una función translogarítmica que muestra la ecuación (12).

$\ln \pi\left(p_{i}, i=1, \ldots, 5, K\right)=\alpha_{o}+\sum_{i=1}^{5} \alpha_{i} \ln p_{i}+\alpha_{6} \ln K+\frac{1}{2} \sum_{i=1}^{5} \sum_{j=1}^{5} \beta_{i j} \ln p_{i} \ln p_{j}+\ln K \sum_{i=1}^{5} \beta_{i 6} \ln p_{i}+\frac{1}{2} \beta_{66}(\ln K)^{2}$

Donde $p_{1}$ indica el precio del producto; $p_{2}$ representa el salario de los Obreros Calificados de Planta; $p_{3}$ indica el salario de los Obreros Calificados Eventuales; $p_{4}$ indica el salario de los Obreros No Calificados de Planta; $p_{5}$ es el

${ }^{15}$ Cabe aclarar que es posible establecer una forma funcional arbitraria como función de producción pero, en el caso de los modelos de demanda laboral, se deben de calcular las demandas de los factores que se deducen de ella. 
ESTIMACIÓN Y ANÁLISIS DE LA DEMANDA LABORAL DE LA

Industria Manufacturera De TlaxCALA, 2002-2003

salario de los Obreros No Calificados Eventuales y $K$ es el Capital. Dado que no se conocía el precio del producto, se utilizó una variable proxy que es el Índice de Precios al Productor. Utilizando el lema de Hotelling se puede llegar a la siguiente forma funcional de beneficio: ${ }^{16}$

$$
\ln \pi=A+\sum_{i=1}^{n} \alpha_{i} \ln x_{i}+\frac{1}{2}\left[\sum_{i=1}^{n} \sum_{j=1}^{n} \beta_{i j} \ln x_{i} \ln x_{j}\right]
$$

Una vez obtenida la forma funcional de los beneficios de la Industria Manufacturera se estiman las demandas de los insumos, que se expresan en la ecuación $(13) .{ }^{17}$

${ }^{16}$ Si la función de beneficio es diferenciable en $p$ y $w$ entonces el lema de Hotelling establece que:

$$
\frac{\partial \pi(p, w)}{\partial(p)}=y(p, w) \text { y } \frac{\partial \pi(p, w)}{\partial\left(w_{i}\right)}=x_{i}(p, w) .
$$

En otras palabras, al diferenciar la función de beneficio con respecto al producto se obtiene la cantidad de producto, mientras que al diferenciar con respecto al precio de un factor en particular se obtiene la cantidad del factor correspondiente. Donde $y$ es el nivel de producto que maximiza el beneficio así como $x_{i}$ es la cantidad del insumo $i$ que lo maximiza. Por lo tanto, el lema de Hotelling permite obtener el nivel de oferta del producto y las funciones de demanda de los insumos al derivar la función de beneficio (ambos resultados existen y son únicos).

${ }^{17}$ Para obtener la ecuación (11) se aplicó el lema de Shephard (1970). El lema establece que si las curvas que originan la función de costos son convexas, entonces el punto que minimiza el costo de un insumo (i) con precio $\left(\mathrm{p}_{\mathrm{i}}\right)$ es único. La idea es que el productor comprará una cantidad única ideal de cada insumo con mínimo precio para obtener un nivel de beneficio, dados los precios de los insumos en el mercado. Sea $x(w, y)$ la demanda condicionada de la empresa del factor $i$. En ese caso, si la función de costos es diferenciable en $(w, y)$ y $w_{i}>0$ donde $i=1 \ldots . n$, entonces:

$$
x_{i}(w, y)=\frac{\partial c(w, y)}{d w_{i}} ; \forall i=1,2, \ldots, n .
$$




$$
\frac{\partial \pi}{\partial p_{i}}=x_{i}
$$

La ecuación (14) es diferenciada con logaritmos naturales para así obtener las proporciones de beneficios y precios de la mano de obra $\left(s_{i}\right)$, que maximizan los beneficios de los factores en la función de demanda laboral que se presenta en la ecuación (15).

$$
\frac{\partial \ln \pi}{\partial \ln p_{i}}=\frac{p_{i}}{\pi} \frac{\partial \pi}{\partial p}=\frac{p_{i} x_{i}}{\pi}=s_{i}
$$

La función de demanda laboral expresada en la ecuación (15) permite obtener la siguiente expresión:

$$
\begin{aligned}
& \ln x_{i}=\ln \left[\alpha_{i}+\sum_{i \neq j} \beta_{i j} \ln p_{i}+\beta_{i i} \ln p_{i}+\beta_{i 6} \ln K\right] \\
& -\ln p_{i}+\left[\alpha_{o}+\sum_{j=1} \ln p_{j}+\alpha_{6} \ln K+\frac{1}{2} \sum_{i=1} \sum_{j=1} \beta_{i j} \ln p_{i} \ln p_{j}+\ln K \sum_{j=1} \beta_{j 6} \ln p_{j}+\frac{1}{2} \beta_{66}(\ln K)^{2}\right]
\end{aligned}
$$

Considerando que la función translogarítmica es una serie de Taylor de segundo orden se tiene que, $\beta i j=0$ para toda $i, j$. Lo anterior permite factorizar la ecuación (16), obteniendo como resultado la siguiente especificación:

$$
\begin{aligned}
& \ln x_{i}=\gamma_{o i}+\gamma_{1} \ln p_{i}+\sum_{j \neq i} \gamma_{j} \ln p_{i}+\gamma_{i 6} \ln K \\
& \gamma_{i 0}=\left(\ln a_{i}+a_{0}\right) \\
& \gamma_{i 1}=\left(a_{i}+1\right) \\
& \gamma_{i}=a_{j} \\
& \gamma_{i 6}=a_{j}
\end{aligned}
$$


ESTIMACIÓN Y ANÁLISIS DE LA DEMANDA LABORAL DE LA

Industria Manufacturera de Tlaxcala, 2002-2003

Por lo tanto, la especificación econométrica que permite estimar la demanda laboral en la industria manufacturera es:

$$
\ln x_{i}=\gamma_{0 i}+\gamma_{1} \ln p_{i}+\sum_{j \neq i} \gamma_{j} \ln p_{i}+\gamma_{i 6} \ln K+u_{i}
$$

Dada la ecuación (18) se pueden derivar las participaciones relativas en cada una de las ecuaciones de insumos de la demanda laboral, que se expresan en el siguiente sistema de ecuaciones:

$$
\begin{aligned}
& \ln x_{2}=\gamma_{02}+\gamma_{21} \ln p_{1}+\gamma_{22} \ln p_{2}+\gamma_{23} \ln p_{3}+\gamma_{24} \ln p_{4}+\gamma_{25} \ln p_{5}+\gamma_{26} \ln K+u_{2} \\
& \ln x_{3}=\gamma_{30}+\gamma_{31} \ln p_{1}+\gamma_{32} \ln p_{2}+\gamma_{33} \ln p_{3}+\gamma_{34} \ln p_{4}+\gamma_{35} \ln p_{5}+\gamma_{36} \ln K+u_{3} \\
& \ln x_{4}=\gamma_{40}+\gamma_{41} \ln p_{1}+\gamma_{42} \ln p_{2}+\gamma_{43} \ln p_{3}+\gamma_{44} \ln p_{4}+\gamma_{45} \ln p_{5}+\gamma_{46} \ln K+u_{4} \\
& \ln x_{5}=\gamma_{50}+\gamma_{51} \ln p_{1}+\gamma_{52} \ln p_{2}+\gamma_{53} \ln p_{3}+\gamma_{54} \ln p_{4}+\gamma_{55} \ln p_{5}+\gamma_{56} \ln K+u_{5}
\end{aligned}
$$

Donde $x_{1}$ representa el nivel de producto; $x_{2}$ expresa a los Obreros Calificados de Planta; $x_{3}$ son los Obreros Calificados Eventuales; $x_{4}$ expresa la variable correspondiente a Obreros No Calificados de Planta; y finalmente $x_{5}$ a Obreros No Calificados Eventuales. Debido a que no se cuenta con el nivel de producto, sólo se estimarán las elasticidades directas e indirectas de los insumos. ${ }^{18}$

Para estimar la ecuación (19), la especificación que satisface las características de la función translogaritmica es la del sistema de ecuaciones aparentemente no relacionadas. Este método econométrico es el que permite obtener los parámetros óptimos de la demanda laboral en la industria manufacturera de Tlaxcala.

\footnotetext{
${ }^{18}$ Para efectos del estudio no afecta la no estimación del nivel de producto.
} 


\section{RESULTADOS}

El procedimiento para la estimación del modelo de demanda de la investigación se explica a continuación.

Primero se realizó una estimación exploratoria con la finalidad de estimar, por separado, cada una de las ecuaciones de demanda laborales (expresadas en la ecuación 18) por medio de un modelo de combinación de corte transversal y serie de tiempo (2002 y 2003), con mínimos cuadrados ordinarios (ver Tabla 6). Los resultados muestran que sólo la elasticidad directa de los Obreros Calificados de Planta tiene un signo negativo (Tabla 6), lo que significa que es un insumo normal. ${ }^{19}$ Las elasticidades directas de los obreros Calificados Eventuales, No Calificados de Planta y No Calificados Eventuales, muestran signos positivos y significativos. ${ }^{20}$

Con relación a las elasticidades cruzadas se observa que, sólo las elasticidades-precio de los Obreros Calificados de Planta, Obreros No Calificados, Obreros Calificados; Obreros Eventuales No Calificados y Obreros Calificados Eventuales son significativas al 1\% y 5\%. Otro resultado importante indica que los Obreros Calificados de Planta son sustitutos de los Obreros No Calificados de Planta, lo que significa que al subir el precio de los primeros se contratan más Obreros No Calificados de Planta. ${ }^{21}$ Además, se encontró evidencia de que los Obreros Calificados Eventuales y No Calificados Eventuales son servicios complementarios; es decir, si aumenta el precio de los primeros se contratarán más Obreros No Calificados Eventuales. ${ }^{22}$ Finalmente, en lo que se refiere al análisis del modelo estimado por la técnica Pool de mínimos cua-

${ }^{19}$ Resultados que concuerdan con lo establecido por Hamermesh (1993) y con Berndt (1991).

${ }^{20}$ Este resultado no es plausible debido a que se indica que los tres tipos de demandas laborales son insumos inferiores. Este resultado significa que las empresas son tan pobres que el porcentaje de los salarios de estas categorías de obreros representan casi todo su ingreso; es decir, al subir el precio de ellos es imprescindible la contratación de los obreros.

${ }^{21}$ Esto no resulta extraño ya que Hamermesh (1993) encuentra tal situación es sus estudios.

${ }^{22}$ Este resultado indica la coherencia que existe con la literatura de la demanda laboral, debido a que los empleos eventuales son empleos que no requieren de un nivel de conocimiento o capacidades altas de la mano de obra. 
ESTIMACIÓN Y ANÁLISIS DE LA DEMANDA LABORAL DE LA

Industria Manufacturera De TlaxcAla, 2002-2003

\section{TABla 6}

\section{Estimación de las demandas laborales mediante el Modelo Econométrico de Combinación de Corte Transversal y Serie de Tiempo (Pooled cross-sections)}

\begin{tabular}{|c|c|c|c|c|}
\hline \multirow[b]{2}{*}{$\begin{array}{c}\text { Variables } \\
\text { Independientes }\end{array}$} & \multicolumn{4}{|c|}{ Variables Dependientes } \\
\hline & $\begin{array}{l}\text { Obreros Calificados } \\
\text { de Planta (a) }\end{array}$ & $\begin{array}{c}\text { Obreros } \\
\text { Calificados } \\
\text { Eventuales } \\
\end{array}$ & $\begin{array}{c}\text { Obreros No } \\
\text { Calificados de } \\
\text { Planta } \\
\end{array}$ & $\begin{array}{l}\text { Obreros No } \\
\text { Calificados } \\
\text { eventuales }\end{array}$ \\
\hline \multirow{2}{*}{$\begin{array}{l}\text { Salario promedio de } \\
\text { Obreros Calificados } \\
\text { de Planta }\end{array}$} & -0.349 & -0.147 & -0.347 & -0.055 \\
\hline & $(3.01)^{* *}$ & $(1.64)$ & $(3.59)^{* *}$ & $(0.55)$ \\
\hline \multirow{2}{*}{$\begin{array}{l}\text { Salario promedio de } \\
\text { Obreros Calificados } \\
\text { Eventuales }\end{array}$} & 0.085 & 0.074 & 0.009 & 0.088 \\
\hline & $(1.75)$ & '(1.96) & $(0.21)$ & $(2.13)^{*}$ \\
\hline \multirow{2}{*}{$\begin{array}{l}\text { Salario promedio de } \\
\text { Obreros No } \\
\text { Calificados de Planta }\end{array}$} & 0.091 & 0.022 & 0.005 & -0.132 \\
\hline & (1.09) & $(0.34)$ & $(0.07)$ & $(1.85)$ \\
\hline \multirow{2}{*}{$\begin{array}{l}\text { Salario promedio de } \\
\text { Obreros No } \\
\text { Calificados Eventuales }\end{array}$} & 0.255 & 0.51 & 0.117 & 1.067 \\
\hline & $(0.84)$ & $(2.18)^{*}$ & $(0.46)$ & $(4.16)^{* *}$ \\
\hline \multirow{2}{*}{ Precio del producto } & 37.424 & 27.7 & 3.392 & -0.332 \\
\hline & $(5.22)^{* *}$ & $(5.08)^{* *}$ & $(0.58)$ & $(0.06)$ \\
\hline \multirow{2}{*}{ Capital actual } & 0.262 & 0.162 & 0.188 & 0.324 \\
\hline & $(4.79)^{* *}$ & $(3.89)^{* *}$ & $(4.19)^{* *}$ & $(7.04)^{* *}$ \\
\hline \multirow{2}{*}{ Año 2002} & -259.113 & -194.067 & -23.615 & -7.133 \\
\hline & $(5.37)^{* *}$ & $(5.29)^{* *}$ & $(0.60)$ & $(0.18)$ \\
\hline \multirow{2}{*}{ Año 2003} & -260.823 & -195.404 & -23.716 & -7.304 \\
\hline & $(5.37)^{* *}$ & $(5.29)^{* *}$ & $(0.60)$ & $(0.18)$ \\
\hline Observaciones & 911 & 944 & 942 & 942 \\
\hline $\mathbf{R}^{2}$ & 0.33 & 0.22 & 0.21 & 0.29 \\
\hline
\end{tabular}

Valor absoluto del estadístico z en paréntesis.

* Significativo al 5\% ** Significativo al 1\%

Fuente: Elaboración propia con datos de SILADERT. 
drados ordinarios, los Obreros No Calificados Eventuales son complemento de los Calificados Eventuales, lo que confirma el resultado anterior. ${ }^{23}$ Un resultado interesante es que las elasticidades-precio del capital son todas significativas y positivas, lo que significa que el capital es complemento de las cuatro categorías de obreros. ${ }^{24}$

En la Tabla 7 se presentan los resultados de las elasticidades directas de los obreros, que son negativas, sugiriendo que son insumos normales. ${ }^{25}$ La elasticidad de los Obreros Calificados de Planta es de 0.293; la de los Obreros Calificados Eventuales, de 0.062; la de los Obreros No Calificados de Planta,

${ }^{23}$ Considerando el estudio de Berndt (1991), se estimó adicionalmente un modelo SUR no restringido de demanda laboral de la industria manufacturera. Primero, se consideró que las elasticidades cruzadas son iguales y que, Obreros Calificados de Planta y los Obreros No Calificados de Planta tienen elasticidades directas positivas. También se estimó el modelo SUR no restringido; la única elasticidad cruzada que es significativa es la que relaciona a los Obreros No Calificados Eventuales de Planta con los Obreros No Calificados Eventuales. Los resultados indicaron que estos dos insumos son complementos, por lo cual coinciden con la teoría. Si sólo se incluye el precio se tiene que, los Obreros No Calificados de Planta son sustitutos de los Obreros Calificados de Planta. Además, se observó que los Obreros No Calificados de Planta son sustitutos también de los Obreros Calificados Eventuales, por lo que el efecto de la eventualidad es mayor que el grado de calificación. De forma semejante a las estimaciones anteriores, los Obreros No Calificados Eventuales son complemento de los Obreros Calificados Eventuales.

${ }^{24}$ Estos resultados concuerdan con Hamermesh (1993), Ingram y Neuman (2003) en lo que respecta a los Obreros Calificados, pero no concuerda con los No Calificados ya que los resultados en otras investigaciones demuestran que son complemento del capital. Las $\mathrm{R}^{2}$ de los cuatro modelos son bajas, alrededor del 0.2 y 0.3 . Se corrieron tres modelos más por el modelo econométrico de combinación de corte transversal y series de tiempo de mínimos cuadrados no ordinarios (MCO) para comparar los resultados.

25 Adicionalmente a esta estimación, se realizaron un conjunto de regresiones exploratorias a fin de validar la especificación del modelo óptimo de demanda laboral. Primero se estimó el modelo de la ecuación (18) sin incluir las variables precio del producto y capital; luego se corrió un modelo que sólo incluye el precio del producto y, finalmente se estimó un modelo considerando sólo el precio del capital. En los tres modelos los signos y magnitudes de las elasticidades directas se mantienen como en el modelo de combinación de corte transversal y series de tiempo con mínimos cuadrados ordinarios, así como la $R^{2}$. El principal resultado de estas exploraciones es que las elasticidades cruzadas varían dependiendo del modelo, a pesar de que no se han considerado restricciones a las elasticidades cruzadas. 
ESTIMACIÓN Y ANÁLISIS DE LA DEMANDA LABORAL DE LA

Industria Manufacturera de Tlaxcala, 2002-2003

de 0.111; y, la de los Obreros No Calificados Eventuales, de $0.12 .{ }^{26}$ Para respaldar aún más las elasticidades estimadas de la Industria Manufacturera de Tlaxcala se observa que, en estudios que utilizan el sistema de ecuaciones con datos agregados o grandes industrias, las magnitudes de las elasticidades no varían en gran medida. ${ }^{27}$

Las elasticidades cruzadas muestran que los Obreros Calificados Eventuales son complemento de los Obreros Calificados de Planta. En este caso no se cumple con lo establecido en la H3. Los Obreros No Calificados Eventuales son complemento de los Obreros Calificados de Planta, de los Obreros Calificados Eventuales y de los Obreros No Calificados de Planta.

En estos resultados se observa que la combinación de las dos dimensiones (planta-eventuales, calificados-no calificados) altera lo propuesto en las hipótesis planteadas ( $\mathrm{H} 2$ y $\mathrm{H3}$ ). Finalmente, un resultado interesante fue la existencia de una constante elasticidad de capital positiva, lo cual significa que el capital es complemento de las cuatro categorías de obreros. Teóricamente esto concuerda con la categoría de Obreros Calificados, ya que la literatura establece que el capital es sustituto de la mano de obra No Calificada. De esto se puede inferir que no hay una brecha significativa entre el nivel de Calificación de los Obreros de la Industria Manufacturera de Tlaxcala. ${ }^{28}$

${ }^{26}$ Hamermesh (1993) encuentra en estudios relacionados con la demanda laboral que, la magnitud de las elasticidades directas varía dependiendo del tipo de datos y del modelo. Para datos agregados o grandes industrias y ecuaciones de factores de demanda, Clark y Freeman (1980) muestran una elasticidad de 0.33 para los trabajadores de producción del Sector Manufacturero (utilizando precios sólo del capital y del salario). Así mismo, Flaig y Steiner (1989) encuentran una elasticidad de 0.14 , usando también sólo el precio del capital y el salario.

27 Berndt (1991), utilizando una función translogarítmica de costo con datos anuales (1947-1971) y usando un modelo de Klein (1953) obtiene una elasticidad directa de trabajo de 0.45; Griffin y Gregory (1976), en un estudio con datos de manufactura de 9 países de la OCDE, que incluye calidad de la ecuación y estima la elasticidad por medio de una función de costos translogarítmica, encontraron que es de 0.23; finalmente, Fuss (1977), utilizando horas trabajadas en la manufactura de diferentes regiones de Canadá para el periodo 1961-1971 y usando un modelo Klein (1953) de costos tanslogarítmico, obtiene una elasticidad de 0.49 .

${ }^{28}$ Adicionalmente a estos resultados, se realizaron estimaciones con un modelo SUR restringido al precio. Se realizó un ejercicio para estimar (empleando el modelo econométrico SUR) los efectos temporales (sin el empleo del término constante). Los resultados de la presente evidencia empírica 
TABLA 7

\section{Estimación de las demandas laborales de la industria manufacturera en Tlaxcala mediante el Modelo Econométrico SUR, restringido por el precio del producto}

\begin{tabular}{|c|c|c|c|c|}
\hline \multirow[b]{2}{*}{ Variables Independientes } & \multicolumn{4}{|c|}{ Variables Dependientes } \\
\hline & $\begin{array}{c}\text { Obreros } \\
\text { Calificados de } \\
\text { planta (a) }\end{array}$ & $\begin{array}{l}\text { Obreros } \\
\text { Calificados } \\
\text { eventuales }\end{array}$ & $\begin{array}{c}\text { Obreros NO } \\
\text { Calificados de } \\
\text { planta }\end{array}$ & $\begin{array}{c}\text { Obreros NO } \\
\text { Calificados } \\
\text { eventuales }\end{array}$ \\
\hline $\begin{array}{l}\text { Salario Promedio de Obreros } \\
\text { Calificados de planta }\end{array}$ & $\begin{array}{c}-0.293 \\
(3.23)^{* *}\end{array}$ & $\begin{array}{c}-0.096 \\
(2.85)^{* *}\end{array}$ & $\begin{array}{l}-0.06 \\
(1.06)\end{array}$ & $\begin{array}{c}-0.198 \\
(3.02)^{* *}\end{array}$ \\
\hline $\begin{array}{l}\text { Salario Promedio de Obreros } \\
\text { Calificados eventuales }\end{array}$ & $\begin{array}{c}-0.096 \\
(2.85)^{* *}\end{array}$ & $\begin{array}{l}-0.062 \\
(2.00)^{*}\end{array}$ & $\begin{array}{l}-0.048 \\
(1.76)\end{array}$ & $\begin{array}{l}-0.066 \\
(2.09)^{*}\end{array}$ \\
\hline $\begin{array}{l}\text { Salario Promedio de Obreros } \\
\text { NO Calificados de planta }\end{array}$ & $\begin{array}{l}-0.06 \\
(1.06)\end{array}$ & $\begin{array}{l}-0.048 \\
(1.76)\end{array}$ & $\begin{array}{l}-0.111 \\
(1.99)^{*}\end{array}$ & $\begin{array}{l}-0.103 \\
(2.09)^{*}\end{array}$ \\
\hline $\begin{array}{l}\text { Salario Promedio de Obreros } \\
\text { NO Calificados eventuales }\end{array}$ & $\begin{array}{c}-0.198 \\
(3.02)^{* *}\end{array}$ & $\begin{array}{l}-0.066 \\
(2.09)^{*}\end{array}$ & $\begin{array}{l}-0.103 \\
(2.09)^{*}\end{array}$ & $\begin{array}{l}-0.12 \\
(\mathbf{1 . 3 6 )}\end{array}$ \\
\hline Capital Actual & $\begin{array}{c}0.387 \\
(9.79)^{* *}\end{array}$ & $\begin{array}{c}0.172 \\
(6.53)^{* *}\end{array}$ & $\begin{array}{c}0.206 \\
(6.56)^{* *}\end{array}$ & $\begin{array}{c}0.298 \\
(7.81)^{* *}\end{array}$ \\
\hline Observaciones & 909 & 909 & 909 & 909 \\
\hline $\mathbf{R}^{2}$ & 0.2903 & 0.1642 & 0.2025 & 0.2721 \\
\hline
\end{tabular}

Valor absoluto del estadístico z en paréntesis.

* Significativo al 5\% ** Significativo al 1\%

Fuente: Elaboración propia con datos de SILADERT.

del modelo completo (incluye precio del producto y del capital) muestra que sólo son insumos normales los Obreros Calificados y los No Calificados de Planta. Al parecer, la eventualidad en los contratos afecta en gran medida y cada vez hay mayor evidencia de que los Obreros Eventuales son insumos inferiores. También se estimó un modelo sin el precio del producto y del capital, y los resultados cambian por completo: las elasticidades directas tienen signo positivo. Este resultado es distinto a lo que comúnmente se obtiene en los trabajos empíricos de demanda laboral, por lo que se sospecha que el precio del producto o del capital están provocando que los parámetros estimados sean sesgados. Además se estimó un modelo SUR restringido considerando sólo el precio del producto, y vuelven a cambiar de signo las elasticidades. Finalmente, se estimó el modelo sólo con el precio del capital, y los resultados indican que las elasticidades calculadas son negativas, tres de ellas significativas al $1 \%$ o al $5 \%$. 
ESTIMACIÓN Y ANÁLISIS DE LA DEMANDA LABORAL DE LA

Industria Manufacturera de Tlaxcala, 2002-2003

\section{CONCLUSIONES}

Los resultados de esta investigación muestran que, el comportamiento de la mano de obra de la Industria Manufacturera de Tlaxcala es semejante al de investigaciones realizadas en el mismo sector pero en otros países. En este sentido, se confirma que la mano de obra de la Industria Manufacturera de Tlaxcala es un insumo normal sin importar el grado de calificación y sin importar el tipo de contrato, ya que las elasticidades directas estimadas son negativas. Igualmente, sus magnitudes son semejantes a las encontradas por Clark y Freeman (1980) y Berndt (1991), de alrededor de 0.3.

En lo que respecta a la mano de obra calificada y a la no calificada, a partir de las elasticidades cruzadas estimadas se obtiene que son insumos complementarios puesto que el signo que presentan es negativo. También, los Obreros No Calificados Eventuales son complemento de los No Calificados de Planta. Al parecer, las diferentes dimensiones de los grupos de obreros afectan la interacción entre ellos.

En un principio se establecieron cuatro hipótesis. La primera establece que todas las categorías de mano de obra de la Industria Manufacturera de Tlaxcala son insumos normales de la producción. Tal hipótesis no se rechaza ya que las elasticidades estimadas son negativas y significativas. La segunda hipótesis propone que la mano de obra calificada es sustituta de los trabajadores no calificados; los resultados muestran que esto no ocurre en la Industria Manufacturera de Tlaxcala porque las elasticidades obtenidas para esta categoría de mano de obra, y sin importar su contrato, son negativas, indicando que son insumos complementarios. La tercera hipótesis, que establece que los trabajadores con contratos eventuales son sustitutos de los no eventuales, se rechaza por la razón antes mencionada.

Con respecto al capital, se obtuvo que es un insumo complementario de la mano de obra tanto calificada como no calificada, sin importar el tipo de contrato. Lo anterior no coincide del todo con lo propuesto por Hamermesh (1993).

Finalmente, se puede concluir que el análisis de la demanda de mano de obra en cualquier sector, en particular la Industria Manufacturera, es de suma 
importancia ya que puede ayudar a la toma de decisiones adecuada de los responsables de las políticas de desarrollo. Por ejemplo, a partir de los resultados anteriores, una política pública que pretenda incidir en el empleo debería controlar variables macroeconómicas que impulsen la inversión en la Industria Manufacturera. Esto ocasionará que la demanda de trabajo aumente dado que el capital y el trabajo de producción son insumos complementarios.

Esta investigación puede dar pie a nuevos proyectos. En un principio, tomando en cuenta que el SILADERT pretende ser un sistema actualizado, se pueden añadir preguntas a la Encuesta a Empresas Manufactureras que capten el consumo de energía, precio de materias primas, nivel de producto y su precio. Estas variables pueden ayudar a una mejor estimación y análisis de la demanda laboral en la producción. Por otro lado, la presente investigación se puede extender a un análisis por región, por rama y/o por tamaño de la empresa.

\section{BIBLIOGRAFÍA}

Arango C. y Rojas A. (2003), "Demanda laboral en el sector manufacturero colombiano: 1977-1999”, Documentos de Trabajo del Banco de la República de Colombia.

Berndt E. R., y Christensen L. R. (1974), "Testing for the Existence of a Consistent Aggregate Index of Labor Inputs”, The American Economic Review.

Berndt, E. (1991), The Practice of Econometrics: Classic and Contemporary, Boston, Mass.: Addison-Wesley Longman, Incorporated.

Carrillo Huerta, Mario M. (2005), La mano de obra para el desarrollo de Tlaxcala, 2003-2005, Vols. I, II y III, San Pablo Apetatitlán, Tlax.: El Colegio de Tlaxcala.

Clark, K. and Freeman, R. (1980), "How Elastic is the Demand for Labor?”, The Review of Economics and Statistics, MIT Press, vol. 62(4), pages 509-20, November.

Court, R.H. y Woods M. (1970), “Testing for Profit Maximization in an Empirical Situation”, International Economic Review, Vol. 11, No. 3. 
ESTIMACIÓN Y ANÁLISIS DE LA DEMANDA LABORAL DE LA

Industria Manufacturera de Tlaxcala, 2002-2003

Dunne, T. (1993), “The Long-run Demand for Labor: Estimates from Census Establishment Data”, Center of Economic Studies, pp. 93-13.

Engenllandt A., y Riphahn R. (2005), “Temporary Contracts and Employee Effort”, Labour Economics, N No12 (2005), pp. 281-299.

Estevão, M. (1999), "Measuring Temporary Labor Outsourcing in U.S. Manufacturing”, NBER Working Paper, 7421.

Flaig G., y Steiner, V. (1989), "Stability and Dynamic Properties of Labor Demand in West German Manufacturing”, Oxford Bulletin of Economics and Statistics, 51(4), pp. 395-412.

Fuss, M. (1977), "Demand for Energy in Canadian Manufacturing”, Journal of Econometrics, No. 5 (Jan): 89-116.

Gagliarducci, S. (2005), “The Dynamics of Repeated Temporary Jobs”, Labor Economics, N²12, pp. 429-448.

Gould J. (1968), “Adjustment Costs in the Theory of Investment of the Firm”, Review of Economic Studies, 35: pp. 47-55.

Green, W. (2003), Econometric Analysis, Prentice Hall.

Griffin, J. M., y Gregory P. (1976), “An Intercountry Translog Model of Energy Substitution Responses”, American Economic Review, No. 66, pp. 845857.

Hamermesh, D. (1992). «A General Model of Dynamic Labor Demand». The Review of Economics and Statistics. Vol 74, No. 4, pp. 733-737. (1993), Labour Demand, Princeton N.J.: Princeton University Press. (1991) "Labor Demand: What do we Know? What don't we know?", NBER Working Paper, No. 3890. (1988), “Data Difficulties in Labor Economics”, NBER Working Paper.

Klein, L. R., (1953), A Textbook of Econometrics, Evanston, Illinois: Row, Peterson \& Co.

Ingram, B. y Neummann G. (2006), “The Returns to Skill”, Labor Economics, No13, pp. 35- 59.

Nickell, S. (1984), “An Investigation of the Determinants of Manufacturing Employment in the United Kingdom”, Review of Economic Studies, 51: pp. 529-557. 
Pecanvel, J. y Craig B. (1994), “The Empirical Performance of Orthodox Models of the Firm: Conventional Firms and Worker Cooperative”, Journal of Political Economy, pp. 718-744.

Roberts, M., y Skoufias E. (1997), "The Long-Run Demand of Skilled and Unskilled Labor in Colombian Manufacturing Plants”, The Review of Economics and Statistics, Vol. 79, N² 2, pp. 330-334.

Sargent, T. (1978), "Estimation of Dynamic Labor Demand Schedules Under Rational Expectations”, Journal of Political Economy, 86: pp. 1009-44.

Shephard, R. (1970), Theory of cost and production functions, Princeton University Press.

Wooldrige, J.M (1999), Econometric Analysis of Cross Section and Panel Data, MIT Press.

Zellner, Arnold (1962), “An Efficient Method of Estimating Seemingly Unrelated Regressions and Test for Aggregation Bias”, Journal of the American Statistical Association, Vol. 57, No. 298, pp. 348-368. 